\title{
El Epísteme del Testigo: El Testimonio de Pablo sobre la experiencia traumática de la vida, pasión y resurrección de Jesús
}

\author{
ML. Maynor Barrientos A. ${ }^{*}$
}

\begin{abstract}
RESUMEN
Este artículo discute las implicaciones del diálogo entre la literatura y los estudios bíblicos, la influencia mutua entre ambas disciplinas y las implicaciones interpretativas a la luz de nuevos conceptos de análisis textual como lo es el epísteme del testigo. Al mismo tiempo se muestra una lectura de la Carta a los Romanos del Apóstol Pablo, quien es interpretado desde la óptica del testigo. A través de esta lectura, se muestra como el testimonio sobre la vida, pasión y muerte de Jesús en tanto experiencia traumática sirve de base para justificar la autoridad (y autoría) del testimonio Paulista.
\end{abstract}

Palabras clave: Episteme, hermenéutica, testigo, fe, lectura.

\section{ABSTRACT}

The Witness' Episteme: Pablo's Testimony about the traumatic experience of the life, passion and resurrection of Jesus. This article discusses the implications of the dialogue between literature and biblical studies, the mutual influence between both disciplines and the interpretative implications in the light of new concepts of textual analysis like The Witness' Episteme. At the same time it shows a reading of the Letter to the Romans from the Apostle Pablo, who is interpreted from the viewpoint of the witness. Throughout this reading, it shows how the testimony about the life, passion and death of Jesus as such a traumatic experience works as a base to justify the authority (and authorship) of the Paulician testimony.

Key words: Episteme, hermeneutics, witness, faith, lecture.

* Maynor Barrientos es parte del equipo de apoyo a la investigación de la Vicerrectoría de Investigación en la UNED. Tiene una maestría en Literatura en Inglés de la Universidad de Costa Rica y ha sido profesor de inglés en la UNED y de composición inglesa y composición avanzada en la UCR. Actualmente se encuentra cursando la maestría en Teología Católica de la UNED. 


\section{Introducción}

\section{El testigo como elemento clave para una hermenéutica bíblica}

El desarrollo del epísteme del lector ha desembocado en muchas otras categorías muy pertinentes para el desarrollo de una hermenéutica bíblica contemporánea. Entre estas categorías sobresale la categoría (o si se quiere el epísteme) del testigo y su testimonio. Pero, ¿en qué medida este nuevo epísteme nos puede arrojar nueva luz en nuestro acercamiento al texto bíblico? ¿Qué elementos interpretativos novedosos podría traer el que adoptemos una postura de lectura desde la posición del testigo? ¿Cuáles son las características propias del testigo que nos podrían ayudar a entender la forma en que las Sagradas Escrituras nos revelan los secretos del plan salvífico de Dios? ¿Qué nuevas formas de relación entre los seres humanos y Dios se pueden establecer a la hora de darle significación al texto bíblico en tanto testimonio de hechos traumáticos? ¿Qué nueva significación alcanzan los hechos revelados en el texto bíblico y qué nos dicen estos hechos de la forma en que interpretamos los hechos que nos afectan cotidianamente? Todas estas son preguntas que esperaremos atender durante nuestra lectura de la Carta a los Romanos, de Pablo.

Para poder atender a nuestro propósito de lectura en este texto, introduciremos la noción y principales características del epísteme del testigo y los alcances de la práctica del testimonio así como de su importancia en la interpretación y construcción de hechos históricos significativos (y principalmente traumáticos) para así poder plantear algunas hipótesis sobre la naturaleza traumática de la vida, pasión, muerte y resurrección de Jesús, y del papel que como testigos de tales eventos cumplieron los discípulos y seguidores de Jesús, principalmente Pablo.

Para poder evaluar dicho efecto, haremos un análisis de la Carta a los Romanos, de Pablo, con el fin de establecer la posición de Pablo como testigo del hecho traumático de la vida de Jesús, de su propias experiencias y del legado escritural de Pablo mismo. Así mismo se sugerirá la posible existencia de una dualidad lector/escritor propia del testigo (y sobre todo del testigo bíblico) con el fin de extender las posibilidades de análisis hermenéutico de la carta de Pablo en tanto texto y lugar de confluencia entre creación e interpretación.

Desde esta perspectiva, podemos observar cómo, en su Carta a los Romanos, Pablo se presenta a sí mismo como testigo del mensaje de Jesucristo, y esboza como sus principales herramientas de testimonio la fe y la razón. Pero, ¿en qué consiste el poder erigirse como testigo de algún evento? ¿Por qué resulta tan importante 
para Pablo el presentarse a sí mismo como testigo de la prédica de Dios?

\section{I}

\section{La teoría literaria y su relación con la hermenéutica bíblica}

Curiosamente, y al margen de los evidentes problemas en el abordaje de una interpretación de una sola vía basada solamente en la búsqueda de un sentido oculto en las páginas del texto (típico de la exégesis bíblica tradicional), en los inicios de las prácticas de teoría, análisis y crítica literaria se hacía patente una tendencia similar a la observada por los cultores de las diferentes técnicas de análisis textual utilizadas por los exégetas de las Sagradas Escrituras; esto es, una predilección por el papel preponderante del autor de la obra literaria (así como el del texto sagrado) y su poder como dador de sentido sobre el texto de su creación y sobre los esfuerzos interpretativos de algún lector o estudioso de los textos.

De la misma forma en que los primeros debates sobre los estudios de exégesis bíblica centraban su discusión prioritariamente alrededor de la noción del autor del texto inspirado y de su infabilidad (o inerrancia), así también en crítica literaria, la figura del autor alcanzó para finales del siglo XIX un status que se sospecharía casi inapelable en su papel de constructor de significación textual. En general, como lo evidencia el pensador francés del siglo XX, Michel Foucault, en las sociedades occidentales se dio un desarrollo importante de la noción (o epísteme) de autor en su función de organizador de textos de toda índole, como también en su función de organizador de un tipo particular de prácticas discursivas. Otras nociones importantes, como la del lector y la del testigo, no fueron desarrolladas ampliamente sino hasta ya entrado el siglo $\mathrm{XX}$.

En términos generales, se podría decir que las prácticas básicas de análisis literario hicieron uso de las principales técnicas y nociones fundamentales de las prácticas exegéticas bíblicas de los grandes maestros de la iglesia cristiana y que esta influencia se mantuvo de forma invariable hasta finales del siglo XIX donde, por primera vez, se comenzó a experimentar un cambio paradigmático.

Sin embargo, a partir del siglo $\mathrm{XX}$, se da un giro muy particular en la relación entre el análisis literario (que para este momento se concentraba en una ciencia naciente llamada teoría literaria) y las prácticas de interpretación exegéticas de las iglesias cristianas. Dicho giro se dio fundamentalmente cuando diferentes círculos y escuelas de análisis literario comenzaron a tomar en cuenta los elementos subjetivos de los lectores y su participación en la construcción del sentido de los textos literarios y de las lecturas que estos hacían de 
dichos textos, a partir de la influencia de la hermenéutica.

Comenzó a darse, en teoría literaria, una revalorización del papel del lector (y por ende del consumidor del texto literario) en la construcción del sentido textual, y al mismo tiempo una desvalorización de la acción del autor de la obra, el cual simplemente se convirtió en un aspecto más de la amplia gama de elementos que hacen del texto literario un entramado sujeto a interpretación. Autores como Barthes llegaron incluso a considerar el uso y la idealización de la noción de autor ampliamente nociva para los estudios literarios:

The author is a modern figure, produced no doubt by our society insofar as, at the end of the middle ages, with English empiricism, French rationalism and the personal faith of the Reformation, it discovered the prestige of the individual, or, to put it more nobly, of the "human person". Hence it is logical that with regard to literature it should be positivism, the epitome and culmination of capitalist ideology, which has attached the greatest importance to the author's "person". The author still rules in manuals of literary history, in biographies of writers, in magazine interviews, and even in the awareness of literary men, anxious to unite, by their private journals, their person and their work; the image of literature to be found in contemporary culture is tyrannically centered on the author, his person, his history, his tastes, his passions; criticism stills consists, most of the time, in saying that Baudelaire's work is the failure of the man Baudelaire, Van Gogh's work his madness, Tchaikovsky's his vice: the explanation of the work is always sought in the man who has produced it, as if, through the more or less transparent allegory of fiction, it was always finally the voice of one and the same person, the author, which delivered his "confidence". (1)

Barthes luego favorece otras categorías textuales (principalmente el texto mismo) con el fin de incrementar las posibilidades de trabajo e interpretación de los textos literarios, haciéndolos, en sus palabras, textos más plurales.

De este modo, se comenzó a dar un proceso de resemantización tanto de las nociones de lector y de texto literario, como también de las prácticas de interpretación, dándose origen a una nueva metodología de análisis textual de tinte claramente hermenéutico. Esto también ocurría en los círculos más radicales de estudio bíblico como lo evidencia ampliamente el Dr. Pablo Richard:

La interpretación latino-americana de la Biblia es un movimiento que crece con fuerza en América Latina, con una hermenéutica liberadora y una literatura propia [...] El pueblo de Dios, organizado en comunidades y movimientos, es el espacio fundamental para interpretar la Biblia, 
con la ayuda de la Exégesis y del Magisterio. Es necesario sin embargo definir cómo el Pueblo de Dios se constituye en sujeto intérprete de la Palabra de Dios. Hoy vivimos en un mundo, donde el sujeto es aplastado como sujeto, tanto en la sociedad como en la iglesia. Especialmente son negados como sujetos los pobres y excluidos, así como las mujeres, los jóvenes, los indígenas, los negros, los campesinos y tantos otros. Un pueblo aplastado y reducido a objeto, no es capaz de interpretar la Palabra de Dios. La construcción del sujeto es una preocupación central hoy en las ciencias sociales, pero aqui haré más bien referencia al pensamiento biblico, donde el sujeto humano creyente se afirma como sujeto en términos de Vida, Espíritu y Libertad. (6)

Se trata de un sujeto lleno del Espíritu pero capaz de aportar significativamente a la construcción del sentido del mensaje bíblico (con la ayuda de las autoridades eclesiásticas) pero totalmente consciente de su vital papel en la realización del mensaje vivo latente en las Escrituras. El sujeto de Richard se acerca mucho a la figura del lector prefigurado en los círculos de análisis literario, sobre todo en el siglo XX a raíz del influjo de la hermenéutica filosófica.

Curiosamente, con la influencia que tuvo el desarrollo de la hermenéutica en el trabajo de análisis textual, tanto en teoría literaria como en disciplinas tan variadas como la semiótica, la psicología, la filosofía (y en buena medida, en casi todas las ciencias sociales) la teología, finalmente, comenzó a verse afectada positivamente, de nuevo, por la hermenéutica en tanto su principal insumo de información y trabajo (su materia prima) lo constituye, de hecho, el propio texto bíblico. De alguna forma, la influencia que había ejercido por centurias el trabajo de interpretación bíblica en la literatura y las formas de organización textual alrededor de la figura del autor, se invirtió con el desarrollo de la hermenéutica de forma tal que ahora esta comienza a influir directamente en el trabajo de interpretación bíblica y la figura del autor comienza, a su vez, a ceder su lugar preferencial a otras figuras o epístemes tales como el texto en tanto entramado textual, el lector, el testigo, entre otras.

\section{II}

\section{Del Autor al Testigo}

La historia del epísteme autor a través de los siglos ha sido ampliamente configurada por autores tan variados como Pierce y Foucault, quienes han rastreado su genealogía hasta la misma figura de los auctores medievales, y el desarrollo mismo de un canon escritural marcado significativamente por el desarrollo canónico eclesiástico del Cristianismo. Este desarrollo nos lleva desde 
la Edad Media hasta culminar con el desarrollo de la crítica moderna de los siglos de la Ilustración, donde alcanza su punto culminante con el surgimiento de nuevos conceptos como el del sujeto trascendental de Kant y la configuración del genio tipificado por el Romanticismo del siglo XIX. Pero no es sino hasta el surgimiento de pensadores claves del siglo XIX que este desarrollo, si se quiere paradigmático, sufre un giro de 180 grados y se comienza a observar un resquebrajamiento de la noción de autor, $y$ en donde asistimos al nacimiento de categorías conceptuales, socio culturales y económicas que dan paso a nuevas figuras y actores que llegaran a nutrir los principales conceptos de la hermenéutica tal y como la desarrollaron autores como Dilthey, Heidegger y posteriormente los filósofos de postmodernidad. De estas la noción de lector es la que más ha sido explorada en las diferentes disciplinas del saber, y por supuesto también en teología.

En estudios literarios, a partir de 1940, la preocupación sobre el papel de los lectores en la construcción crítica de los significados de los textos creció hasta el punto de establecerse toda una corriente de pensamiento dedicada a analizar todos los elementos referentes al lector, el acto propio de lectura y de interpretación, y a cada una de las respuestas psicológicas y conductuales del sujeto lector enfrentado directamente al texto por ser leído. Es importante resaltar que el camino hacia la valoración de lector ha sido largo y altamente dificultoso. Un intento de trabajo genealógico nos llevaría indudablemente a considerar profundas transformaciones a lo largo de la historia en campos tan diversos como la política, la filosofía, la geopolítica, la economía, las revoluciones científicas y tecnológicas, etc. En el campo filosófico, por ejemplo, es notoria (así como fue también el caso para el epísteme del autor) la influencia de Immanuel Kant y todos los demás pensadores del idealismo alemán, quienes introdujeron en la palestra del pensamiento occidental una noción de sujeto muy robusta. El sujeto transcendental del idealismo alemán se erige totalmente autónomo y como condición necesaria del principio de construcción de realidad. Sin él sería imposible que hubiese conocimiento, moral o libertad.

En el campo político, es indudable la importancia que tuvieron los cambios sociales y territoriales durante el Renacimiento, y justo después del descubrimiento de América y la exploración del continente africano, lo que vino a alterar para siempre los mapas geopolíticos del mundo, los cuales no han cesado de cambiar desde entonces. Igualmente, en el siglo XIX, el nacimiento de nuevas disciplinas científicas dedicadas principalmente al estudio de los grupos humanos como la biología, la lingüística, la economía, entre otras, 
modificaron sustancialmente nuestra forma de entender y concebir a los seres humanos, sus relaciones y sus diferentes contextos e historiografías.

Sin embargo, es indudable que para la noción del lector (y posteriormente para la noción del testigo, que veremos más adelante a propósito del testimonio bíblico de Pablo), uno de los eventos históricos trascendentales fue sin duda el proceso de alfabetización y extensión de la educación que experimentaron las sociedades occidentales durante los siglos XVIII, XIX y XX. Con niveles de alfabetización muy bajos, era impensable que el papel del lector hubiese cobrado actualidad, ya que el trabajo de interpretación de los textos (no solo los textos sagrados, pero principalmente estos) fue tarea exclusiva de tan solo unos cuantos. Sin embargo, con el gran desarrollo educativo y con los avances tecnológicos en materia de producción y comercialización de libros y textos de una gran variedad (los avances en las tecnologías de la imprenta y el establecimiento de grandes casas editoriales y de medios de información más baratos como el periódico), el número de lectores posibles creció a tal punto que se volvió insostenible el hecho de que cada vez mucho más personas de diferentes campos del saber se acercaran a los textos literarios canónicos con nuevos ojos, y con ello, con nuevas interpretaciones. Lo mismo sucedió en relación con las Sagradas Escrituras.
Lo que siguió fue un creciente interés, no solo de diseminar el acceso a los textos literarios y bíblicos entre un mayor número de lectores y estudiosos, sino que también se plantearon preguntas y cuestionamientos importantes a las principales interpretaciones que de dichos textos se habían hecho y que se habían también considerado canónicas o inapelables.

Este largo proceso, no ha hecho más que enriquecer el trabajo de interpretación textual en literatura así como también en teología, como ya se ha mencionado a propósito de la hermenéutica. Hemos podido, gracias a él, tener acceso a un mayor número de fuentes y metodología de investigación escritural, lo que ha redundado en nuestro mejor entendimiento de la revelación que Dios ha hecho de sí mismo en el texto sagrado. Esto ha sido posible en gran parte por el testimonio que de sus experiencias directas o indirectas con la revelación divina han hecho, a lo largo de la historia, considerable número de personas y actores.

Podemos decir, en este sentido, que los primeros grandes lectores del mensaje de salvación y de la nueva alianza propuesta por Dios a los seres humanos a través de su hijo Jesucristo, fueron precisamente aquello que lo oyeron hablar y predicar en la Palestina del siglo I. Fueron los apóstoles, y los allegados más cercanos a Jesús, los primeros testigos de su mensaje $y$, obviamente, los primeros 
en transcribir sus interpretaciones personales (sus lecturas acuciosas), por medio de los hermosos testimonios de vida que nos legaron, sin los cuales no hubiésemos penetrado en el misterio de salvación. Estos mismos personajes se transformaron en los primeros lectores del mensaje de Jesucristo y los primeros que, desde sus propias condiciones culturales y sociales construyeron juntos el significado de aquellas palabras.

Cualquier lector o intérprete de cualquier texto, a sabiendas que este quiera transmitir sus impresiones al resto de personas que le escuchen o lean, se convierte a su vez en un testigo ocular de los acontecimientos narrados en estos textos, por lo que participa desde su composición subjetiva en parte creadora del sentido de los textos interpretados por él.

Considero relevante que nos avoquemos a revisar en detalle las teorías que acerca del testigo se han hecho con el fin de poder hacer una lectura más enriquecedora del texto sagrado, en particular de una de las epístolas de Pablo para poder evaluar de qué forma, el texto Paulista nos da evidencia del papel de Pablo como testigo y cómo este papel adoptado por él nos ayuda a comprender la propia interpretación que Pablo hace del mensaje de Jesús desde su posición de lector del "texto" de Jesús, y por ende del "texto" o plan salvífico de Dios.

\section{III}

Para John D. Peters la noción del testigo posee claramente tres fuentes fundamentales: la ley, la teología y la atrocidad (708). Para Shoshana Felman y Dori Laub el testimonio se convierte en el elemento principal de evidencia para el establecimiento o esclarecimiento de una crisis en el devenir de los acontecimientos históricos y personales. Precisamente los dos contextos más comunes para los cuales los grupos y organizaciones humanas se sirven de la noción del testimonio son los referentes a un juicio, en donde existe una crisis de intereses que debe ser esclarecida por medio de los relatos de los testigos del hecho, y, por otro lado, en la clínica donde las descripciones de los hechos, cuyo impacto y poder traumatológico obligan a los testigos a dar su testimonio, son las herramientas principales que le permiten a los pacientes de la terapia psicológica o psicoanalítica poder curarse a sí mismos de las consecuencias ejercidas por estos hechos sobre su constitución subjetiva.

Tales serían los casos para Pablo quien, coincidentemente, se presenta a sí mismo como testigo de dos eventos entrelazados entre sí: el juicio marcado por la crisis originada por la diferencia de criterios entre judío cristianos obediente de la ley hebrea tradicional y amantes del revolucionario mensaje de Jesús, y los 
cristianos gentiles que no obedecen la ley judía a pesar de que Jesús fuera hebreo, pero que, por medio de su fe en Jesús, adoptaron el cristianismo; en segundo lugar, Pablo se presenta como testigo de un evento altamente traumático como lo fue la pasión, muerte y posterior resurrección de Jesús, y encarna él mismo tal sufrimiento por medio de su propia experiencia de dolor.

Tanto para Peters, como para Felman y Laub, existe una estrecha relación entre el escritor de un texto literario y el testigo que da algún testimonio. En ambos casos, tanto el escritor como el testigo, se constituyen en fuentes creadoras de un relato (o por mejor decir, de una narrativa), con una alta dosis de significación y de trascendencia tal, que muchos eventos históricos se han sucedido a toda cuenta por el impacto que pudo haber tenido el relato de algún testigo o el escrito formal de algún escritor. En el caso mismo del cristianismo, pocos podrían dudar de la importancia que tuvo la misión evangelizadora de los apóstoles y allegados a Jesús, los cuales no hicieron uso más que de sus testimonios acerca de los hechos y dichos del Nazareno para poder, a partir de su predica, ayudar a todos los otros seres humanos de la tierra a entender y constatar por sí mismos las verdades sobre el plan de salvación y la redención de los pecados. Tampoco se podría dudar de que fueron, justamente esos testimonios, los primeros ejemplos de lo que llegaría a constituirse en el acervo bibliográfico del Nuevo Testamento. Además no olvidemos que se podría afirmar que el mismo Antiguo Testamento forma, en su integridad, una suerte de testimonio anticipado de los eventos que tendrían, luego, lugar en el siglo I.

Es evidente el recalcar que, efectivamente, estos primeros testimonios de los apóstoles se centran casi exclusivamente alrededor de grandes eventos, que podríamos considerar traumáticos, o que causaron gran impacto en las mentes de las personas que fueron testigos de su esplendor. Consecuentemente, podríamos afirmar, como lo hacen Felman y Laub, que existe una fuerte relación entre el acto mismo de atestiguar y los actos de lectura y escritura de los textos. Al ser testigo ocular, el testigo hace una lectura de los acontecimientos que observa, gravando en su memoria los pormenores de dichos eventos, para luego reescribirlos durante el relato que de estos sucesos hace, por así decirlo, en la sala de juicios.

In considering, in this way, literature and art as a precocious mode of witnessing -of accessing realitywhen all other modes of knowledge are precluded, our ultimate concern has been with the preservation, in this book, both of the uniqueness of experience in the face of its theorization, and of the shock of the unintelligible in the face of the attempt at its interpretation; with the 
preservation, that is, of reality itself in the midst of our efforts at interpreting it and through the necessary process of its textualization.

No solamente se inscribe el acto del testigo en un proceso de textualizacion de la realidad de los hechos atestiguados, sino que se reconoce el status de exclusividad del testimonio como única herramienta de acceso a la realidad referida, allí donde cualquier otra posibilidad de registro de hechos es imposible, a pesar de que dicho testimonio está lejos de ser en sí mismo enteramente concluyente como nos lo recuerda Peters. Los eventos atestiguados poseen por ende la cualidad de convertirse ellos mismos en la "memoria" de los hechos incluidos en la narrativa del testigo. De ahí que, cuanto más traumáticos son los hechos para el testigo, más grande será la impresión dejada por los eventos en la memoria del testigo, la cual, a su vez, se instituye como el único acceso posible para la reconstrucción de los eventos y, por ende, en la memoria per se de los propios eventos atestiguados.

Felman no duda en caracterizar el siglo XX como un "siglo postraumático", que ha sido testigo de las más ignominiosas fatalidades de la guerra (principalmente la II Guerra Mundial) y, por consiguiente, el siglo XX sería el siglo del testimonio por excelencia. El análisis que hace Felman de la literatura postraumática del siglo XX, la lleva a creer en los poderes sanadores del testimonio, pero además a dibujar una dimensión pedagógica relacionada con él. Para Felman es imperioso que los seres humanos del siglo XX puedan aprender de las catástrofes a las que se han expuesto, de manera tal que se puedan comenzar a sanar las heridas. Para ella, debe establecerse una relación entre el testimonio y la pedagogía de manera tal que se puedan enriquecer las personas y todas las disciplinas del saber de las experiencias narrativas de los testigos. Se establece así una interesante relación entre la práctica textual, la pedagogía y la clínica, todo esto a partir de la práctica del testimonio.

Es imperioso, por consiguiente, desde la actividad del testigo, comprender la constitución subjetiva de la persona que atestigua un evento cualquiera sobre el cual luego dará su punto de vista, así como las condiciones culturales y capacidades cognitivas que le vayan a permitir hacer abstracción de los hechos que ha observado, para luego deducir enseñanzas posibles $\mathrm{y}$, finalmente, las condiciones de afectación mental y física a las cuales se haya podido enfrentar durante su exposición a hechos tan traumáticos como una guerra, una hambruna o el daño físico al que pueda haber sido sometido.

Otra característica del testigo se refiere a la inexorable soledad que experimenta después de haberse 
sometido al trauma del evento que atestigua. Solamente el testigo del hecho podrá dar testimonio de su percepción del hecho, sin que este testimonio pueda ser idénticamente transmitido por una plétora de otros testigos. La experiencia del testigo ante el evento traumático es totalmente particular y nunca podrá ser enteramente compartida por ninguna otra persona. A pesar de que la validez de su juicio puede ser confirmada por la constatación de este en relación con el testimonio de otros testigos, no cabe posibilidad de que la narración de dos testigos pueda coincidir en todos los detalles del hecho en relación con sus relatos. Esto puede ser fácilmente verificado con un rápido repaso de los cuatro evangelios principales de la cristiandad, todos ellos incluidos en el Nuevo Testamento.

Por consiguiente, existe una estrecha relación personal entre el testigo y su narración de los hechos de tal forma que incluso una persona podría ser totalmente caracterizada a partir de la forma en que rinde testimonio. Así, en un juicio, por ejemplo, algún testigo podría ser considerado como una persona honesta o deshonesta solamente a partir de la evaluación de su testimonio. ¿De qué forma, sino a partir de esta realidad, pudieron los primeros Padres de la iglesia cristiana determinar el valor veritativo de los textos sagrados cuando tuvieron que escoger los más representativos, aquellos que finalmente llegaron a ser parte de las Sagradas Escrituras tal y como las conocemos ahora?

Pero, aún cuando los aspectos personales del testigo pueden enteramente ser juzgados a partir exclusivamente de sus relatos, según Felman, Levinas, Peters y otros, otra particularidad del testigo es que "testifica sobre lo que ha sido dicho a través de él" (Felman 1992: 3). En otras palabras, la narración del testigo (que lo define ampliamente), lo supera al mismo tiempo y nos habla además de eventos que están más allá del alcance narrativo del testigo. El testimonio no solamente nos habla del testigo y lo delimita sino que también nos habla de los eventos en sí, de las situaciones contingentes alrededor de los eventos, de las crisis precedentes y posteriores al evento, de las maquinarias bélicas, de la psicología y contextos socio políticos y culturales de las demás personas que participan de los eventos, y de un número mayor de cosas, e información de las cuales los testigos si acaso de enteran, y mucho menos podrían llegar a intentar entender en toda su complejidad.

Así que, a toda cuenta, las narraciones de los testigos se transforman en una fuente inagotable de información valiosa que, en el momento en que fueron plasmadas en el testimonio, escapan a todo poder de decisión y control del testigo. El testigo nos dice de cosas que de repente él mismo hubiese, si estuviese consciente de ello, evitado o preferido no 
incluir en su relato. De esta forma, evidencia, a través de su testimonio, cualidades tanto de un lector como además también de un escritor. Se comporta como un lector al darle forma significativa a la serie de hechos, eventos, sonidos, y mensajes a los cuales se enfrenta, de manera tal que construye todo un entramado de significados que adquieren para él trascendencia simbólica muy particular y ante la cual reacciona también de manera muy particular. Se encarga de interpretar, por medio de una lectura detallada de todo ese material simbólico, una realidad que le es inmediata y que, a la vez, se le presenta ajena y distante, pero que, finalmente, terminará dándole forma a su propia subjetividad. No podría, dicho de otra forma, existir un testigo sin que antes se hubiese dado una lectura.

Por otro lado, el testigo se comporta como un escritor que, con base en el material simbólico a su alcance, construye un relato que es el fundamento estructural de su testimonio a partir de la experiencia con lo atestiguado. El testigo, entonces, construye un texto que compartirá con alguien más siempre a partir de una lectura vivencial, lo que hace que su producción literaria sea también palabra viva. El texto escrito por el testigo es particular porque entabla una especie de fotografía del evento, pero también incluye los detalles de su propia constitución significativa como autor de ese texto. Su texto es una especie de biografía de sí mismo, de sus temores y afecciones. Es un escritor ampliamente dependiente de su obra, ya que en ella se entrañan las claves que le pueden llevar al propio entendimiento de sí.

Pero, simultáneamente, a pesar de esta dualidad estructural del testigo, él es también diferente de un lector y de un escritor. El testigo posee la particularidad de que no puede, aunque lo desee, pensarse fuera de la fabricación de su propio testimonio. Fuera de la sala de juicios o del despacho psicoanalítico, la constitución subjetiva del testigo se diluye entre el resto de la gente que le ve pasar. $\mathrm{Su}$ existencia, como testigo de un hecho, está inseparablemente unida a la existencia e importancia de su testimonio. Un lector o un escritor cualquiera podría sin problemas desprenderse, separarse constitutivamente de su lectura u obra literaria cualquiera, sin que esto conlleve una disolución de su subjetividad. Si bien es cierto tanto el lector como el escritor se fabrican al mismo tiempo que su lectura y obra en el momento mismo del acto de lectura y escritura, una vez finalizado ese acto, el lector original podría tomar otra posición constitutiva (dígase la de un autor, por ejemplo) sin ningún problema. García Márquez es escritor en tanto su relación de autor con Cien Años de Soledad, pero lector en tanto efectúa una lectura de esa obra cumbre, sin que ningún aspecto de la subjetividad 
constitutiva se vea en peligro. Sin embargo, ¿podría Pablo, o cualquier otro evangelista, separarse de su papel como testigo clave de la obra y los dichos de Jesús, y adoptar otra posición al margen de su testimonio sin que, por ello, nuestra comprensión del sujeto Pablo no sufra alteraciones fundamentales?

\section{IV}

\section{Lectura de la Carta a los Romanos de Pablo desde la posición del testigo}

Como ya hemos visto, Pablo se presenta a la comunidad con la que se comunica, no desde la postura de un escriba o de un autor de teorías nuevas o a partir de un simple lector de antiguos textos. Por el contrario, la posición de Pablo es clara en sus epístolas: se presenta a sí mismo como un testigo. Tanto en la epístola a los Romanos como la primera de Corintios, Pablo desde un inicio de presenta como un "testigo" escogido por Dios y Jesucristo para la prédica de sus verdades y hechos, así como un lector del mensaje de Dios en las escrituras:

Pablo siervo de Jesucristo, Apóstol por vocación divina, escogido para predicar el Evangelio de Dios, Evangelio que el mismo Dios había prometido anteriormente por sus profetas en las santas Escrituras, acerca de su Hijo Jesucristo nuestro Señor, que le nació según la carne del linaje de David (Rom. 1: 1-3).

Continuamente estoy dando gracias a Dios por vosotros por la gracia de Dios, que se os ha dado en Jesucristo: porque en él habéis sido enriquecidos con toda suerte de bienes espirituales, con todo lo que pertenece a los dones de la palabra de la ciencia: habiéndose asi verificado en vosotros el testimonio de Cristo (Cor. I 4-6).

Desde esta posición de testimonio, Pablo pretende servir de testigo para dos clases de eventos: una primera clase, se refiere a eventos que para él, como para el resto de la comunidad cristiana, se consideran altamente traumáticos. Se trata de la vida, pasión, muerte y posterior resurrección de Jesús, en primera instancia, pero también de la experiencia traumática vivida por el mismo Pablo quien, si bien no presenció la crucifixión de Jesús, fue testigo de su grandeza por medio de su propia experiencia traumática mientras perseguía a grupos de cristianos, y al mismo tiempo de la persecución a la que, por su predica como cristiano, él mismo y las iglesias con las que se corresponde han sufrido. Así en Romanos I: 12 nos dice:

Quiero decir, para que hallándome entre vosotros podamos consolarnos mutuamente los unos a los otros, por medio de la fe que es común a vosotros y a mí. 
Mientras tanto, en algunas otras líneas, la referencia es al evento traumático de la muerte de Cristo cuyo misterio se accede por medio de la fe:

Porque todos pecaron y tienen necesidad de la gloria y la gracia de Dios. Siendo justificados gratuitamente por la gracia del mismo, en virtud de redención que todos tienen en Jesucristo, a quien Dios propuso para ser la víctima de propiciación en virtud de su sangre por medio de la fe (Rom. III: 23-25).

Tanto el sacrificio de Jesús en la cruz como su resurrección (como eventos traumáticos) se convierten, en la predica de Pablo, elementos esenciales de la fe y la redención de los pecados.

$Y$ el espiritu de aquel Dios, que resucitó a Jesús de la muerte, habita en vosotros: el mismo que ha resucitado a Jesucristo de la muerte, dará vida también a vuestros cuerpos mortales, en virtud de su Espiritu que habita en vosotros (Rom. VIII: 11).

La fe expuesta por Pablo se basa fuertemente en el atestiguamiento de hechos maravillosos tanto en la figura humana y divina de Jesús (su muerte en cruz y su resurrección) como también experimentada por él mismo, cuando perdió su vista y fue testigo de la grandeza de Dios a quien perseguía sanguinariamente. Pablo, entonces, ha sido escogido por Dios para dar testimonio en dos niveles: uno de naturaleza escatológica y el otro a nivel muy personal. Tal es el nivel de compromiso de Pablo en estos dos niveles de predica testimonial, que incluso toda su personalidad y constitución subjetiva (física y mentalmente) se ha visto modificada para así adaptarse a su nueva condición de testigo de hechos asombrosos. Por un lado, Pablo cambió su ocupación, sus bienes, actividades primarias y comportamientos, visión de mundo y entendimiento de los acontecimientos de los cuales tendría si acaso alguna referencia y, por otro lado, al cambiar incluso hasta su propio nombre (Saúl), Pablo completa también su transformación psicológica.

Igualmente, a través principalmente de la epístola a los Romanos, Pablo también se nos presenta como testigo de un juicio. Existe, como se puede leer fácilmente en su carta, un conflicto entre los judíos conversos y los gentiles que, aunque cristianos de corazón, no encontraban razón para seguir la ley judía que había sido, muy particularmente por cierto, obedecida por el mismo Jesús como judío. De hecho la mayoría de líneas de la carta Pablo las dedica a interceder en este tema el cual, en el siglo I, fue un debate ardiente. La intención de Pablo es tratar de suavizar la disputa entre unos y otros, dando testimonio de fe a partir de su experiencia personal con Jesús; es este, y no el problema de la ley, el elemento más importante en la 
comprensión del plan de salvación y de redención de Dios. Las referencias al juicio de Dios son constantes en la epístola y Pablo está sencillamente actuando en esta misiva como testigo en ese juicio de salvación.

Que no me avergüenzo yo del Evangelio; siendo él, como es, la virtud de Dios para salvar a todos los que creen: a Judíos primeramente, y después a los Gentiles. Y en el Evangelio es en donde se nos ha revelado la justicia que viene de Dios, la cual nace de la fe, y se perfecciona en la fe, según aquello que está escrito: el justo vive por la fe. (Rom. I: 16-17)

Jesucristo me es testigo de que os digo la verdad y mi conciencia da testimonio en presencia del Espiritu Santo, de que no miento, al aseguraros que estoy poseido de una profunda tristeza, y de continuo dolor en mi corazón, hasta desear yo mismo el ser apartado de Cristo por la salud de mis hermanos (Rom. IX: 1-3).

Además de ser un juicio donde se escarmienta a los judíos fuertemente, este juicio atestiguado por Pablo es también un juicio de sanación, integrándose en Pablo la triple dimensión del testimonio, tanto como narrativa de hechos relevantes a un juicio, como relevantes a un hecho traumático, como también, finalmente, elemento de la clínica.

Pero además de esta tridimensionalidad del testimonio paulista, este apóstol por vocación actúa como maestro dándoles además una función pedagógica en su misiva a los Romanos. Pablo, iluminado por el Espíritu de Dios, quiere darle una lección de vida a todos aquellos que se disputan la exclusividad de la salvación por su condición de judío o por su condición de persona de fe. Esta lección de vida es constitutiva del acto de fe como vía primordial para alcanzar el misterio de salvación. Así lo plantea Pablo en su carta a los Romanos:

Por lo que os exhorto a todos vosotros, en virtud del ministerio que por gracia se me ha dado: a que en vuestro saber o pensar, no os levantéis más alto de lo que debéis, sino que os contengáis dentro de los límites de la moderación: según la medida de la fe que Dios ha repartido a cada cual. (Rom. XII: 3)

La dimensión pedagógica de las cartas de Pablo son características de la función del testigo quien busca por lo general crear conciencia de lo trágico o beneficioso de los eventos que testimonia.

Tanto para completar esta misión como para lograr exhortar a sus correspondientes, Pablo insiste en la necesidad de cultivar un principio de fe fundamental. La veracidad del testimonio de los testigos, más que poderse aseverar por medio de la verificación empírica, constituye un verdadero acto de fe por parte de los oyentes y del propio 
testigo. Estos deben estar convencidos de que la narración de los hechos atestiguados sean veraces para que así el testimonio pueda servir su función cabalmente. No hay que olvidar que el testimonio de Pablo inscrito en sus cartas es la única vía de acceso a la realidad que persigue dibujar, por lo que Pablo debe contar con su propia fe en la veracidad de su propio testimonio, como también debe contar con la fe de quienes lo escuchan y leen.

$\mathrm{Su}$ testimonio nos habla no solo de la grandeza del acto de Dios y el sacrificio hecho por Jesús para redimir de los pecados de todos los seres humanos, sino que también nos habla de la integridad personal de Pablo, de su gran fe en Dios y su vocación de servicio a la causa emprendida por Jesús para la redención de todos. Nos habla también de un Pablo con don de autoridad, capaz de simpatizar con el dolor y las dudas de los demás, ya que él mismo ha podido experimentar ese mismo dolor y las mismas dudas. Nos habla de un hombre que siente un alto respeto por las leyes y las costumbres de las comunidades con las que se comunica y de un hombre capaz de hablarle al corazón de todos los miembros de esas comunidades. Nos habla también en su testimonio de una profunda comprensión de los eventos asombrosos de los cuales quiere dar fe y los cuales describe con un poder de convencimiento magistral, lo que hace de su prédica una lección inolvidable de profunda solidaridad humana.

$Y$ así nosotros como más fuertes en la fe, debemos soportar las flaquezas de los menos firmes y no dejarnos llevar de una vana complacencia por nosotros mismos. Al contrario cada uno de vosotros procure dar gusto a su prójimo en lo que es bueno, y puede edificarle. Considere que Cristo no buscó su propia satisfacción, antes bien como está escrito decía a su Padre: los oprobios de los que te ultrajaban vinieron a descargar sobre mí. Porque todas las cosas que han sido escritas en los Libros Santos, para nuestra enseñanza se han escrito a fin de que mediante la paciencia y el consuelo que se saca de las Escrituras, mantengamos firme la esperanza (Rom. XV: 1-4).

Por ser su testimonio la única fuente a la realidad de los hechos de los cuales Pablo ha servido como testigo de fe y, a la vez, sirve de única fuente verdadera de acceso a la propia mente y corazón de Pablo como hombre de fe en Dios, no es de extrañar que este Apóstol haya elegido el formato de escritura, quizás, más personal que tenía a mano: el formato de la epístola. Como sabemos bien, el testimonio de Pablo no nos ha llegado en forma de evangelio como el de los otros testigos de los actos y palabras de Jesús (Marco, Juan, Lucas y Mateo, por ejemplo, aun cuando sí contamos con epístolas de otros 
apósteles y allegados a Jesús como Pedro, o Santiago).

La forma de escritura epistolar es de los formatos de comunicación más privadas y personales que se tienen. Es una forma de escritura en donde el autor mantiene un nivel de confianza, amor y de entera confidencialidad con sus lectores, de manera tal que para un testigo se constituye en la mejor herramienta para transmitir todas las impresiones que los sucesos atestiguados han causado en su mente.

Es la forma perfecta para mejor resguardar la memoria de todos los eventos narrados por el testigo, ya que, por la intensa devoción con que se escriben, existe un deseo denodado por mantener la certeza de lo que se está describiendo o enseñando. Es una forma de escritura tan personal como lo fueron en el Antiguo Testamento y en otras fuentes de cultos antiguos, los salmos y cánticos de alabanza, donde los creyentes entregaban una parte de sí muy apreciada a su Dios. Pablo, consciente de ello no duda en equiparar su prédica por medio de las cartas con su predica exhortativa o con estos otros medios de agasajo:

Por eso publicaré joh Señor! entre las naciones tus alabanzas, y cantaré salmos a la gloria de tu nombre. $Y$ en otro lugar, alegraos, naciones, en compañia de los Judios que son su pueblo. Y en otra parte, alabad todas las gentes al Señor, y ensalzadle los pueblos todos (Rom. XV: 9-11).

Pablo pretende crear una comunidad sólidamente unida por medio de la fe en el testimonio que ha recibido de otros, y en el testimonio que él mismo ha dado de los sucesos relacionados con la vida, muerte y resurrección de Jesús. Es precisamente de esta forma como Pablo cierra su hermosa epístola a los Romanos con toda la fuerza de su testimonio:

Gloria a aquel que es poderoso para fortaleceros en mi evangelio, $y$ en la doctrina de Jesucristo que yo predico, según la revelación del misterio de la redención: misterio que después de haber permanecido oculto en todos los siglos pasados, acaba de ser descubierto por los oráculos de los profetas, conforme al decreto del Dios eterno, y ha venido a noticia de todos los pueblos para que obedezcan en su fe (Rom. XVI: 25-26).

Pablo instaura todo un voto de fe con base en eventos que para la buena mayoría de personas en el siglo I fueron de un gran impacto. Tal tuvo que haber sido la impresión que las palabras, hechos de Jesús, su vida en general, su pasión y muerte $\mathrm{y}$, finalmente, su resurrección y legado salvífico y eclesiástico, que estos hechos (y los testimonios de quienes dieron fe de su veracidad) lograran perduran con la misma intensidad hasta nuestros días. 
No existe en la historia de la humanidad otro ejemplo singular con la fuerza transformadora que tuvieron las obras de Jesús. Su vida debió, por consiguiente, haber estado llena de situaciones tan profundamente traumáticas y llenas de sabiduría, de tal forma que se justifique el sinnúmero de testimonios que surgieron a partir de ellas. Como nos lo plantea el Papa Benedicto XVI en la introducción a su libro Jesús de Nazaret:

En Él se ha hecho plenamente realidad lo que en Moisés era sólo imperfecto: Él vive ante el rostro de Dios no sólo como amigo, sino como Hijo; vive en la más íntima unidad con el Padre.

Sólo partiendo de esta afirmación se puede entender verdaderamente la figura de Jesús, tal como se nos muestra en el Nuevo Testamento; en ella se fundamenta todo lo que se nos dice sobre las palabras, las obras, los sufrimientos y la gloria de Jesús. Si se prescinde de este auténtico baricentro, no se percibe lo específico de la figura de Jesús, que se hace entonces contradictoria $y$, en última instancia, incomprensible. La pregunta que debe plantearse todo lector del Nuevo Testamento sobre la procedencia de la doctrina de Jesús, sobre la clave para explicar su comportamiento, sólo puede responderse a partir de este punto. La reacción de sus oyentes fue clara: esa doctrina no procede de ninguna escuela; es radicalmente diferente a lo que se puede aprender en las escuelas. No se trata de una explicación según el método interpretativo transmitido. Es diferente: es una explicación "con autoridad". Al reflexionar sobre las palabras de Jesús tendremos que volver s-obre este diagnóstico de sus oyentes y profundizar más en su significado (28-29).

Esto quiere decir, además, que debemos volver de nuevo a la reacción que causaron las obras y palabras de Jesús sobre sus oyentes. Debemos volver a los testimonios que describen esas reacciones y examinar, como en el caso de Pablo, la manera en que dichas acciones y afecciones nos hablan de una realidad cuyo acceso nos sería imposible de no contar con los relatos de los testigos de Jesús.

Mucho del entendimiento del cual nos habla Su Santidad dependerá de la forma en que accedamos al relato heredado por los testigos de tales acontecimientos y de la caracterización que podamos hacer de sus motivos, trazos psicológicos y sus contextos histórico sociales, de su temores y fortalezas, por medio del trabajo hermenéutico que nos permiten hacer los actuales avances en estudios textuales a partir de muchas disciplinas que se ha estado informando entre ellas. Pero, principalmente, nos sería de mucha ayuda si, al tiempo que nos convertimos en lectores de dichos textos, también completáramos su poder significativo con el aporte de nuestro propio testimonio 
sobre el valor veritativo de esa realidad que se vuelve algo caprichosa entre las manos de los testigos.

\section{Bibliografía}

Barthes, R. The Death of the Author. Southern Methodist University. http://faculty.smu. edu/dfoster/theory/barthes.html

Casiano, J. 1983. "Exégesis Bíblica, Hermenéutica y Teología". Ediciones.

Universidad de Navarra: Pamplona. En antología Nuevo Testamento: Contexto histórico-literario. UNED, 2007.

Felman, S. and Dori Laub. 1992. Testimony: Crises of Witnessing in Literature, Psychoanalisis and History. Routledge : New York.

Foucault, M. 1984. The Foucault Reader. Ed. Paul Rabinow. Pantheon Books: New York.
Kant, Immanuel. 2001. Crítica de la razón práctica. Alianza Editorial: Madrid.

Manucci, V. 1985. La Biblia Como Palabra de Dios. DDB : Bilbao.

Peters, John D. 2001. "Witnessing". Media Culture Society. 23; 70.

Ratzinger, J. Material exclusivo para estudiantes del programa de Maestría en Teología Católica. UNED. 2007.

2007. Jesús de Nazaret. Planeta: Colombia.

Richard, P. En antología Nuevo Testamento: Contexto histórico-literario. UNED, 2007.

Ricoeur, P. 1996. "On Interpretation”. The Continental Philosophy Reader. Routledge: New York.

Sagrada Biblia de la Familia Católica. Ediciones Marfil: Santa Fe de Bogotá, Colombia, 1993. 
